\title{
Designing effective training programs according to the needs of human resources (Case Study in the General Directorate of Municipalities)
}

\author{
Mostafa Naif Jameel and P. Dr. Nadhum Jawad Abid \\ Higher Diploma equal to Master in Municipalities Management in the Department of Business Administration \\ University of Baghdad, Iraq. mostafanaif80@gmail.com , alzeidinadhum@gmail.com
}

\section{Introduction}

\begin{abstract}
The research aims to study and analyze the possibility of designing effective training programs according to the human resource needs of the General Municipalities Directorate, and to demonstrate the availability of the requirements of the scientific method of training by measuring the level of the gap between the actual reality of a training activity in the directorate and the checklist. The research problem is determined by the fact that the researched organization is a service agency that has direct contact with the citizen's life. It needs individuals with distinguished knowledge and skills to work for it, as well as the need to improve, develop and develop the capabilities of these individuals working for it. The five-scale check list was used for the purpose of collecting data to identify the level of actual application within the research community, and to identify the main and secondary causes of the gap, using the cause and effect diagram (Ishikawa diagram).

The results of the analysis showed that there is a gap in training requirements with regard to designing training programs, and a number of conclusions were reached, the most prominent of which was a weakness in the training activity, especially with regard to designing training programs. As for the recommendations, the most prominent of which are the adoption of the scientific method in training and the design of effective training programs that meet the needs and aspirations of human resources.

Keywords: Designing training programs, training needs, systematic training process, human resources.
\end{abstract}

Article Received: 23 ${ }^{\text {th }}$ February 2021, Revised: 20 March 2021, Accepted: 07 April 2021

\section{Introduction}

Organizations seek to achieve a high level of quality, by preparing human resources to perform the duties and tasks entrusted to them within the specified timeframe and the quality of the required work, and there is no doubt that training is a vital activity. The nature of the required training based on identifying the training needs of individuals and designing effective training programs according to a systematic, scientific and studied method.

The research problem is represented in how to design effective training programs that meet the actual needs of workers in the General Municipalities Directorate as one of the service directorates that have direct contact with citizens, and this requires the directorate to possess human resources that receive high-level training and possess knowledge and skills to provide services in proportion to the aspirations of citizens.

\section{First - the research problem:}

The research problem stems from how to design effective training programs that meet the actual training needs of human resources in the General Municipalities Directorate as one of the service directorates that have direct contact with the citizen and this requires that the above directorate possess human resources that possess knowledge, skills and trends at a high level to provide services in line with the aspirations of citizens, This requires that this training process be subject to a scientific study and analysis.

And based on the fact that the nature of service provision is based primarily on the human resource, the researched organization must 
evaluate its human resources to provide accurate information and a scientific, professional and objective basis to determine the actual training needs for the purpose of designing training programs that meet those needs and in light of this the research problem is determined in answering the questions. The following:

1- Are there specific criteria for determining the training needs in the researched organization?

2- Do the results of determining the training needs in the researched organization contribute to the design of the required training programs?

3- What is the nature of the implemented training programs, and do they contribute to meeting the actual training needs of the researched organization?

\section{Second - Importance of research:}

The importance of research is highlighted by focusing on the following aspects:

1. The organization research assisted in determining the target groups that require training.

2. Research contributes to assisting the organization to design effective training programs for employees comply with their actual needs, desires, aspirations and functional tasks.

3. Research contributes to providing a scientific and sound basis for a successful training process.

\section{Third - Research methodology:}

The research depends on the approach of case study and is one of the descriptive studies based on many data collection and information on one individual or a limited state of cases with the aim of the focus of the deepest understanding of the studied and similar phenomenon, where data collects on the current situation of the case, motion and relations In order to understand the deepest and better understanding through the provisions collection and various documents and records and interviews, and the researcher is one of the workers in the Directorate of Public Municipalities and has knowledge of the work of the Directorate, and through personal interviews with human resources management and training to find out the actual application Training with regard to the design of training programs and identifying needs in the organization, The checklist was used to analyze the strengths and weaknesses, determine the performance gap, the disease plan and the result (Ishikawa scheme) to identify the main and secondary cause of them, and then develop the conclusions and recommendations to them to be done for the design of effective training programs to meet the actual needs of human resources.

\section{Fourth - Training Concept:}

Training is a major element of great importance in administrative development (AlSakarneh, 2011: 17-18). Therefore, it needs careful planning, follow-up and implementation to achieve the required goals, so that the individual can perform his work in an effective manner and with positive behavior and directions. In view of the global technological and economic progress and the tendency of organizations to expand and open up, the need for functional cadres trained and qualified to keep pace with this development has increased.

In view of the great development and diversity of products and services in the era of communication and information and the increasing importance of business development, work has become complex and diversified due to the emergence of works of a new nature and the disappearance of other works of an old nature, as information and experience have become a creative subject related to the science of organizing information and with the analytical mind that is constantly learning, until The training and education process at the present time has become focused on providing the trainee / learner with knowledge, skills, behaviors and attitudes regarding how to learn, so that the trainee or learner is a trainer or teacher for himself.

There are many definitions of the concept 
of training as defined by (Noe et al., 2018: 201) is the planned efforts of the organization to help employees acquire knowledge, skills, abilities and behaviors related to the job, with the aim of applying them in the job.

And defined by (Dessler,2017: 240) describes the process of teaching new or existing employees the basic skills they need to do their jobs.

\section{First - the systematic training process:}

Effectiveness of the training process. Effective training requires the use of a systematic training process. The figure below illustrates the four stages of a structured approach: identifying training needs, designing training programs, delivering training, and evaluating training. Using such a process reduces the likelihood of unplanned, uncoordinated, and random training efforts. (Mathis \& Jackson, 2010: 260)

The first topic: the theoretical side

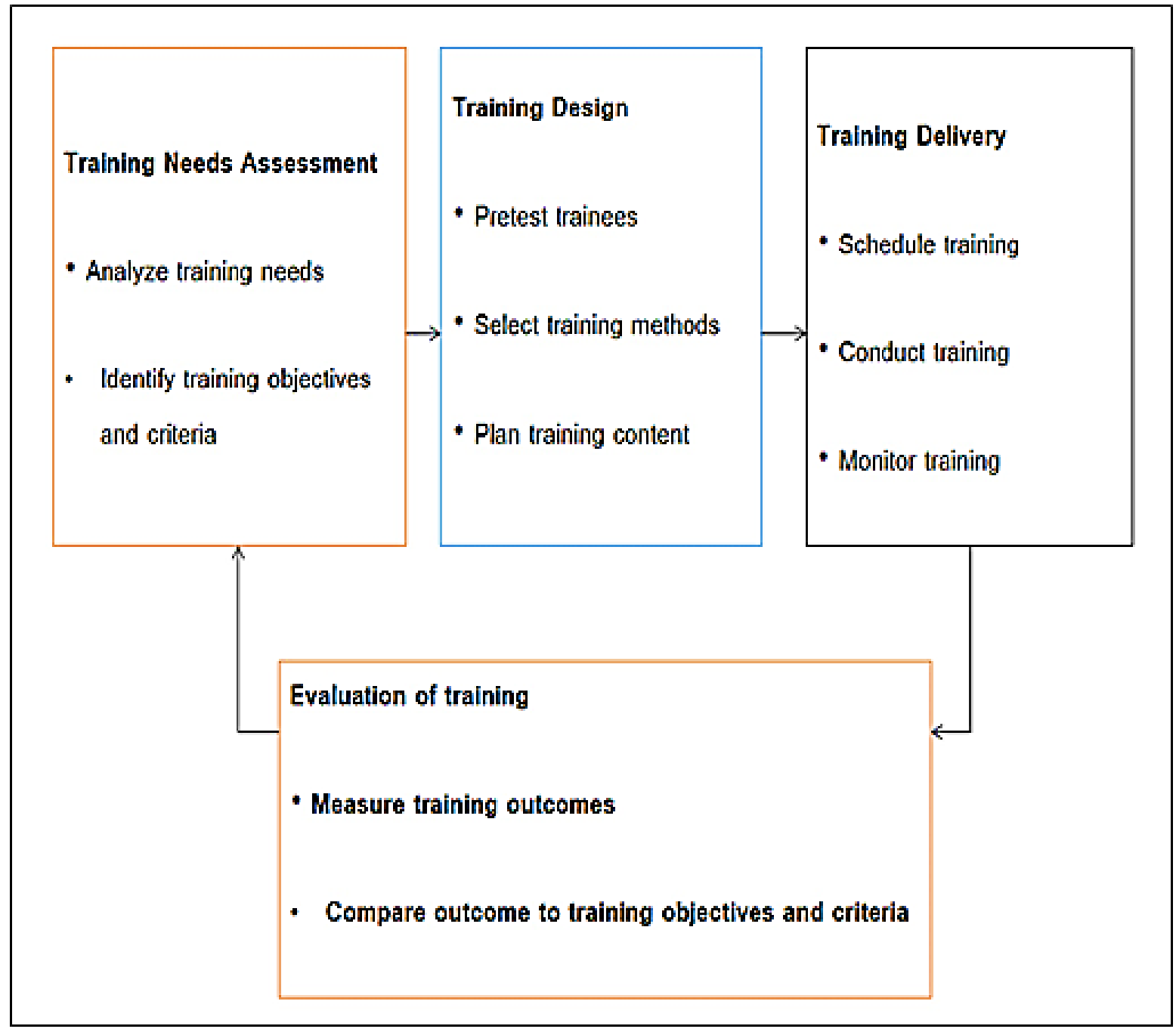

Figure (1) - the systematic training process

Source: Robert L. Mathis \& John H. Jackson,(2010),Human Resource Management, $13^{\text {th }}$ ed

\section{1- Determining the training needs}

The first step in the training process, the identification and assessment of needs, refers to the process used to determine whether training is necessary. The figure below illustrates the causes 
and consequences resulting from the needs assessment. As we can see, many different 'pressure points' indicate that training is essential. These pressure points include performance problems, new technology, internal or external customer requests for training, job redesign, new legislation, changes in customer preferences, new products, or employees 'lack of basic skills as well as support for the company's business strategy (eg. And expanding global business). Note that these pressure points do not guarantee that training is the correct solution. Consider, for example, a delivery van driver whose job is to deliver anesthetic gases to medical facilities. The driver accidentally connects a light anesthetic supply line to the hospital oxygen system supply line, contaminating the hospital's oxygen supply. Why did the driver make this error that is clearly a performance issue? The driver may have done so due to a lack of knowledge about the proper plug line for anesthesia, or outrage over a required pay increase that his manager had recently refused, or the lack of signs on the valves to connect the gas supply. Only a lack of knowledge can be addressed through training. Other pressure points require addressing issues related to the outcome of good performance (pay system) or work environment design. (Noe et al., 2010: 276).

A needs assessment usually includes an organization analysis, an individual analysis, and a task analysis. Organization analysis takes into consideration the context in which the training will take place. This means that the analysis of the organization includes determining the suitability of the work for training, given the organization's work strategy, its available resources for training, and the support by managers and peers for training activities.

Analyzing an individual helps determine who needs training. Analyzing an individual (1) involves determining whether deficiencies in performance are due to a lack of knowledge, skill, or ability (a training problem) or a motivational problem or a work design problem. (2) Determine who needs training. (3) Determine the extent to which employees are prepared for training. Task analysis involves identifying important tasks and the knowledge, skill and behaviors that must be emphasized in training employees to complete their tasks.

In practice, organization analysis, individual analysis, and task analysis are not usually done in any specific order. However, since organization analysis is concerned with determining whether training fits with the strategic objectives of the organization and whether the organization wants to allocate time and money to training, it is usually conducted first. People analysis and task analysis are often done simultaneously because it is often difficult to determine whether performance deficiencies represent a training problem without understanding the tasks and work environment.

What are the results of the needs assessment? As shown in the figure below, a needs assessment shows who needs training and what the trainees need to learn, including the tasks they need to train on as well as the knowledge, skills, behavior, or other job requirements. A needs assessment helps in determining whether an organization will purchase training from a vendor or consultant or develop the training using internal resources. (Noe et al., 2010: 277). 


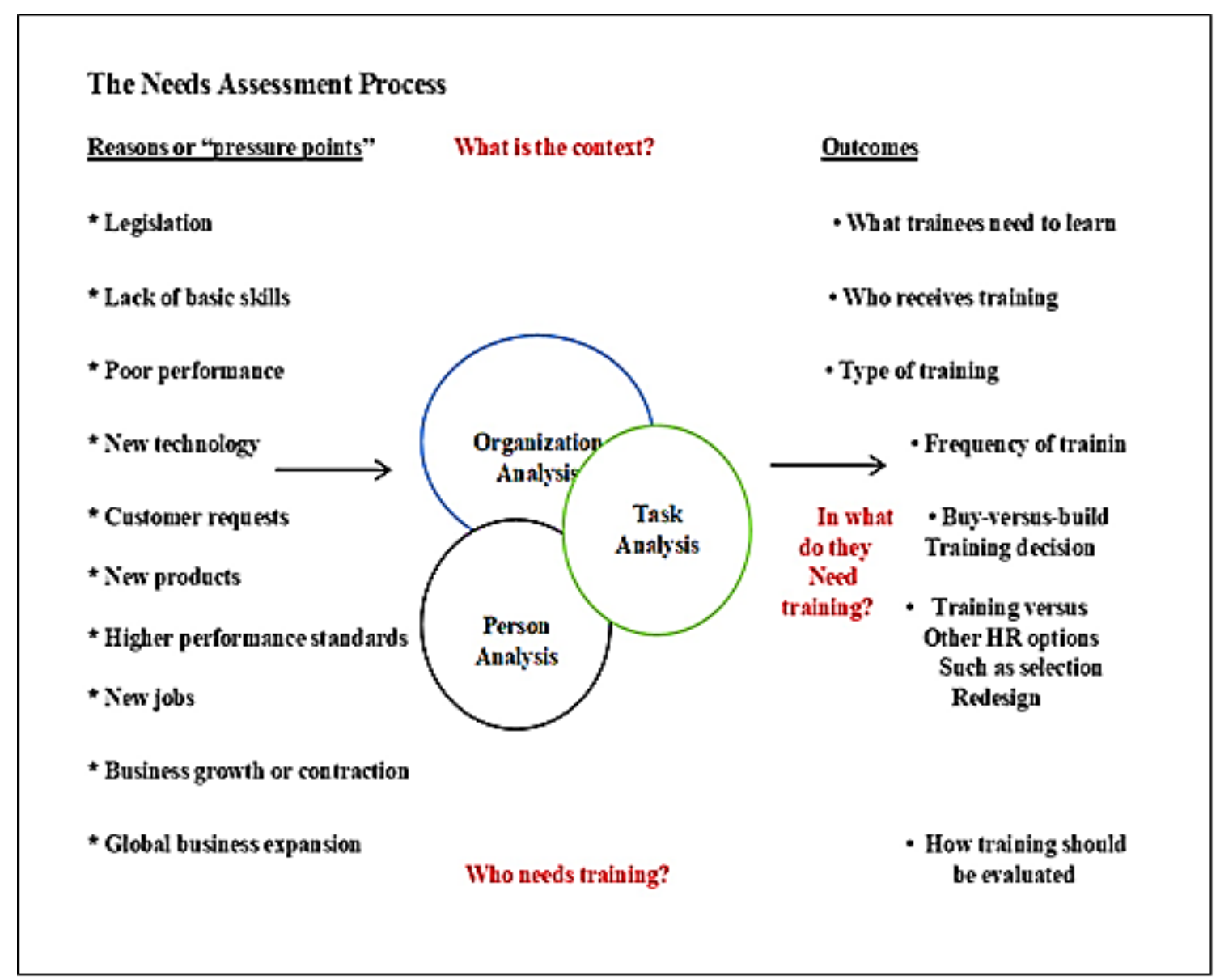

Figure (2) - The process of assessing or identifying training needs

Source: Noe ,Raymond A., Hollenbeck ,john R. , Gerhart, Barry ,Wright „Patrick M.(2017)," Human

Resource Management Gaining A competitive Advantage" , 10 ed

\section{2- Designing the training program}

Based on the results of the needs analysis, the manager then designs the training program. Design means planning the overall training program including the objectives of the training, methods of delivering it, and evaluating the program. Substeps include setting performance goals, creating an outline of training (all steps of the training program from start to finish), choosing a program delivery method (such as lectures or web), and checking the overall program design with management. The design should include summaries of how you are planning a training environment that motivates trainees to learn and transfer what they have learned to the job. Hence also the manager reviews the potential training program content (including workbooks, exercises, and activities), and estimates the training program budget. If the software is to use the technology, the manager should include a review of the technology he plans to use as part of the analysis. They will also decide how to organize the various training content components, choose how to evaluate the program, create a comprehensive summary plan for the program, and obtain management approval to move forward (Dessler, 2016: 230). 


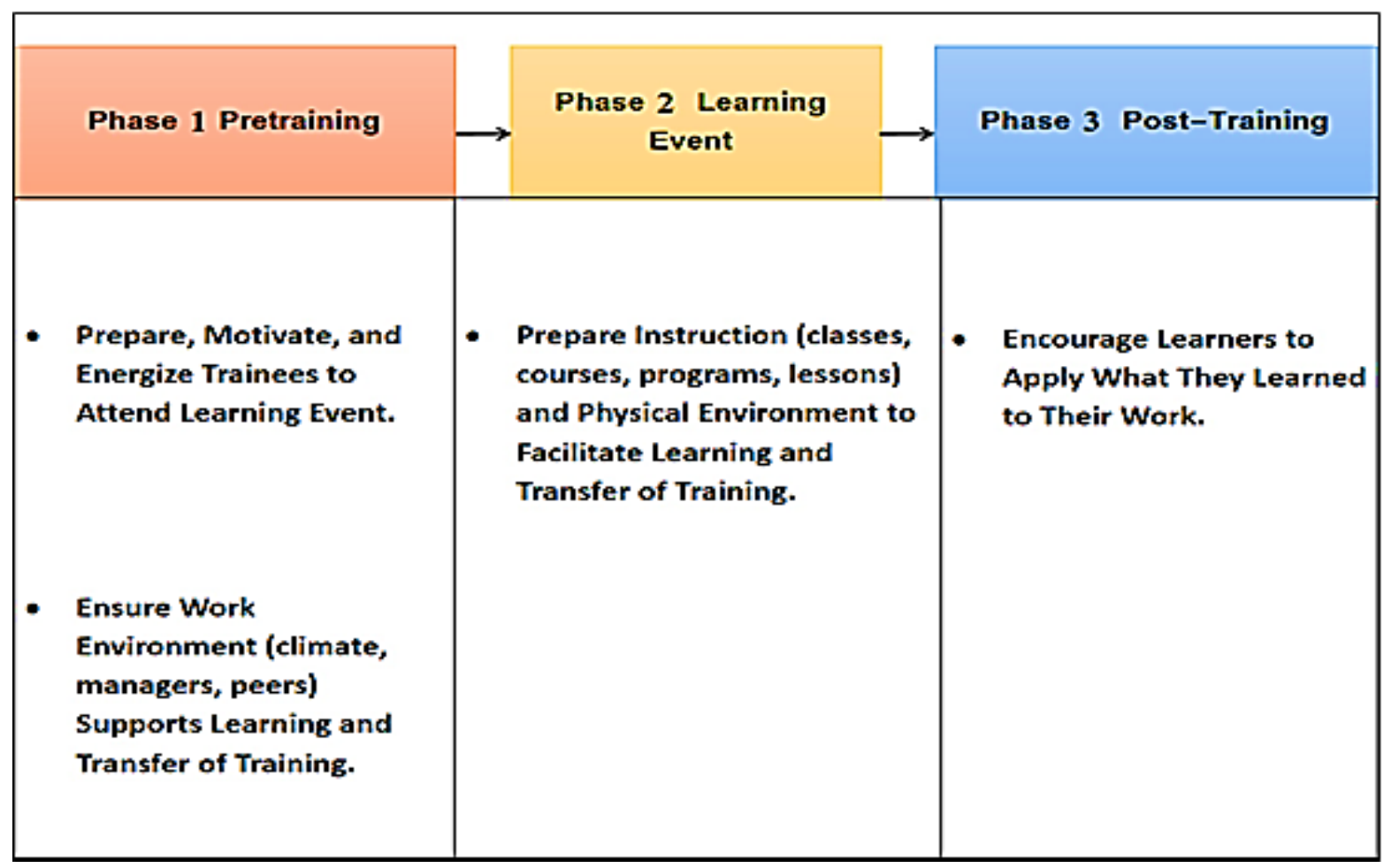

Figure (3) - Training program design process

Sources: Based on J. Zenger, J. Folkman, and K. Sherwin, “The promise of phase 3," T+D (January 2005): 31-34; R. Hewes, "Step by Step", T+D (February 2014): 56- 61; J. Halsey, "How to ENGAGE and bring out the brilliance in everyone," From www .trainingmag.com, the website for training magazine, accessed August 3, 2011. (Noe,2017:203(

\section{3- Training delivery}

Once the training is designed, the actual delivery of the training can begin. Regardless of the type of training being conducted, a number of methods and methods can be used to deliver it. The growth of training technology continues to expand the options available, as shown in the figure below (Mathis \& Jackson, 2010: 266-267).

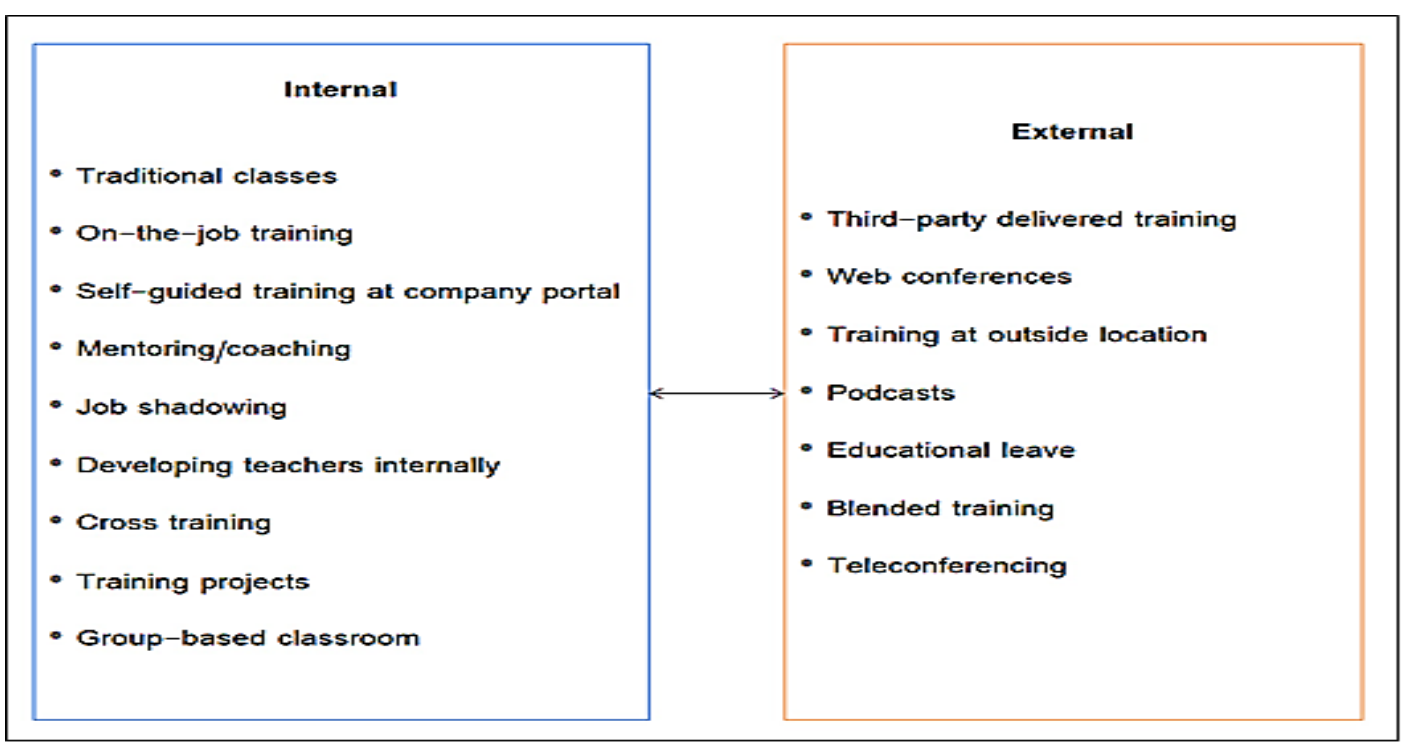

Figure (4) - Training delivery options

Source: Robert L. Mathis \& John H. Jackson,(2010),Human Resource Management, $13^{\text {th }}$ ed 
Whatever approach is used, a variety of considerations must be weighed when choosing methods of delivering training. The common variables considered are:

- The nature of the training.

- Subject.

- The number of trainees.

- The individual versus the team.

- Training resources / costs.

- E-learning versus traditional learning.

- Geographical locations.

- Allocated time.

- Timetable for completion.

To illustrate, a large organization with many new employees may be able to direct employees using the Internet, videos, and specific HR personnel, while a small organization with few new employees may have an HR officer meeting individually with new hires for several Hours. A medium-sized organization with three locations in a geographic area can bring the supervisors together for a two-day training workshop once every three months. However, a large global organization may use web-based courses to reach moderators around the world, with the content available in several languages. Training is frequently conducted internally, but some types of training use external training resources or technology.

Moreover, training can be formal or informal. Formal training is visual, as it consists of planned learning activities. Informal training occurs when learning is not the primary focus, but it does happen anyway. Informal learning may be the result of some kind of self-effort or just chance, but it often happens as needed.

\section{4- Evaluation of the training program}

Measuring training results After the training program ends, or at intervals during the training program, organizations should ensure that the training meets the goals. The preparation stage for training program evaluation is when the program is developed. Besides designing the course objectives and content, the planner must determine how achievement of the objectives will be measured. Depending on the objectives, the evaluation could use one or more of the measures shown in the figure below, trainee satisfaction with the program, acquired knowledge or capabilities, use of new skills and behavior on the job (training transfer), improvements in the individual and organizational performance. The usual way to measure whether participants have access to the information is to take tests on paper or electronically. Coaches or supervisors can observe if the participants demonstrate the required skills and behaviors. Surveys measure changes in attitudes. Changes in company performance have a variety of metrics, many of which are tracked by organizations to prepare performance appraisals, annual reports, and other routine documents in order to show the ultimate measure of success shown in Figure Return on investment (ROI) (Noe et al., 2016: 222). 


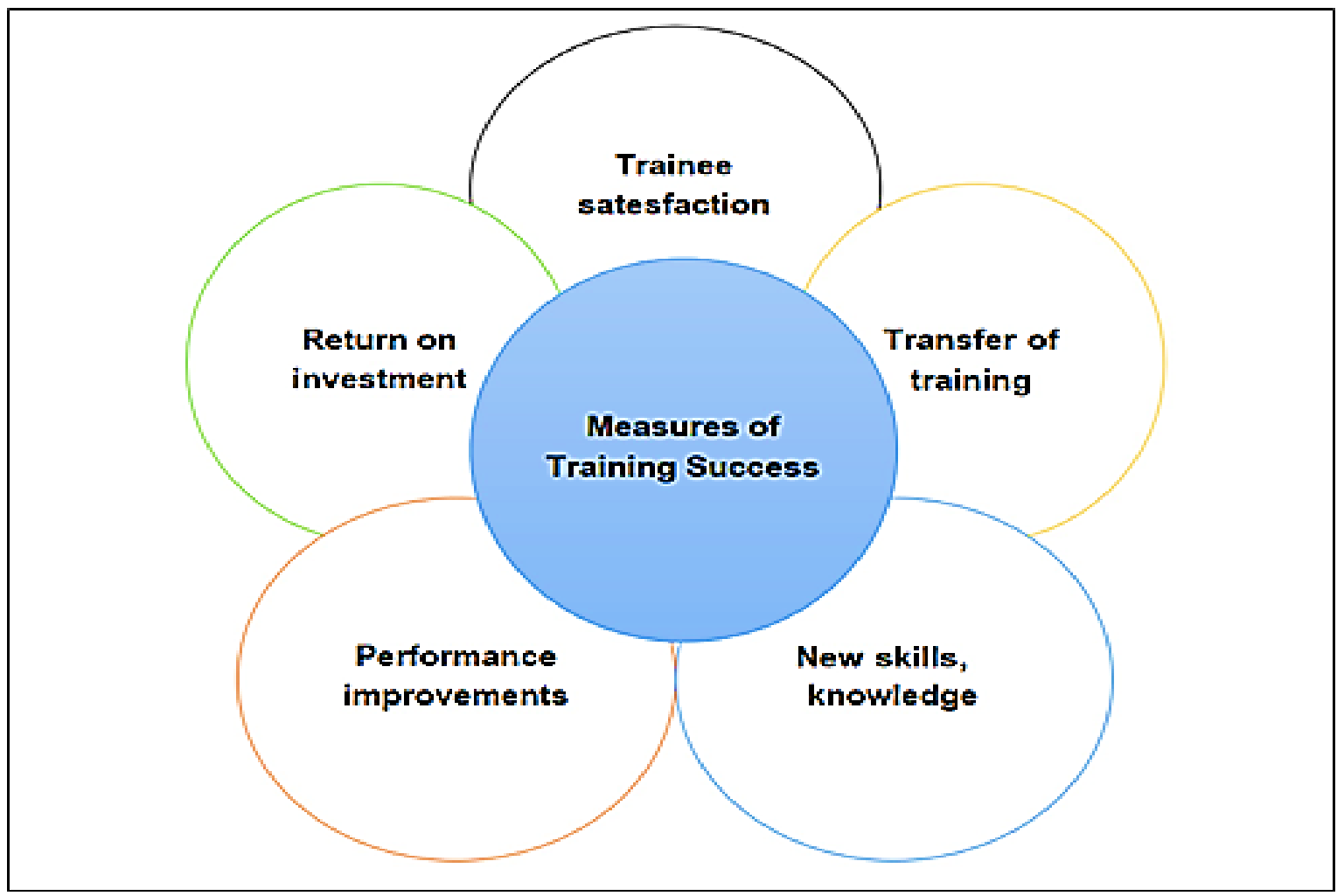

Figure (5) measures of training success

Source: Noe .Raymond A., Hollenbeck .john R. , Gerhart. Barry ,Wright .Patrick M. (2016)," Fundamentals of Human Resource Management " , 6th Edition , Published By McGraw -Hill Education New York.

The second topic: the practical side

- The reality of the training process in the research organization and the possibility of its evaluation:

1- Designing training programs
The checklist related to (designing training programs) shows the extent of convergence or divergence of the activity of this requirement in the training process for the researched organization according to the questions contained in that paragraph, and as shown in Table (1).

Table (1)

Checklist for the implementation of training program design in the research organization

\begin{tabular}{|l|l|l|l|l|l|l|}
\hline & Designing training programs & $\begin{array}{c}\text { Not } \\
\text { Applicabl } \\
\mathrm{e}\end{array}$ & $\begin{array}{c}\text { Poorly } \\
\text { applied }\end{array}$ & $\begin{array}{c}\text { Kindly } \\
\text { implemente } \\
\mathrm{d}\end{array}$ & $\begin{array}{c}\text { Partially } \\
\text { applied }\end{array}$ & $\begin{array}{c}\text { Fully } \\
\text { implemented }\end{array}$ \\
\hline $1-$ & $\begin{array}{l}\text { The Training Department } \\
\text { designs training programs to } \\
\text { meet the required training } \\
\text { needs. }\end{array}$ & & & \\
\hline
\end{tabular}




\begin{tabular}{|c|c|c|c|c|c|}
\hline $2-$ & $\begin{array}{l}\text { The Training Department, } \\
\text { through designing training } \\
\text { programs, does the following: } \\
\text { A- Designing the necessary } \\
\text { activities to close the } \\
\text { training gap }\end{array}$ & $\checkmark$ & & & \\
\hline & $\begin{array}{l}\text { B- Determining the } \\
\text { criterion for evaluating } \\
\text { training results. }\end{array}$ & & & $\checkmark$ & \\
\hline & $\begin{array}{l}\text { C- Determining the } \\
\text { appropriate method for } \\
\text { monitoring the } \\
\text { implementation of } \\
\text { training. }\end{array}$ & $\checkmark$ & & & \\
\hline 3- & $\begin{array}{l}\text { The training department } \\
\text { determines the objectives } \\
\text { required of the training } \\
\text { program: } \\
-\quad \text { Informations } \\
-\quad \text { Knowledge } \\
-\quad \text { Skills } \\
-\quad \text { Trends } \\
-\quad \text { Behavior }\end{array}$ & & & & $\checkmark$ \\
\hline 4- & $\begin{array}{l}\text { The Training Department } \\
\text { practices designing training } \\
\text { programs and follows the } \\
\text { following steps: } \\
\text { A- The department creates } \\
\text { and develops training } \\
\text { content }\end{array}$ & & & $\checkmark$ & \\
\hline & $\begin{array}{l}\text { B- The department } \\
\text { determines the sequence } \\
\text { and order of the training } \\
\text { program topics }\end{array}$ & $\checkmark$ & & & \\
\hline & $\begin{array}{l}\text { C- The department } \\
\text { determines the timing of } \\
\text { the training program }\end{array}$ & $\checkmark$ & & & \\
\hline & $\begin{array}{l}\text { D- The department } \\
\text { determines the place and } \\
\text { time of the training }\end{array}$ & & & & $\checkmark$ \\
\hline & $\begin{array}{l}\text { E- The department selects } \\
\text { qualified trainers }\end{array}$ & & $\checkmark$ & & \\
\hline
\end{tabular}




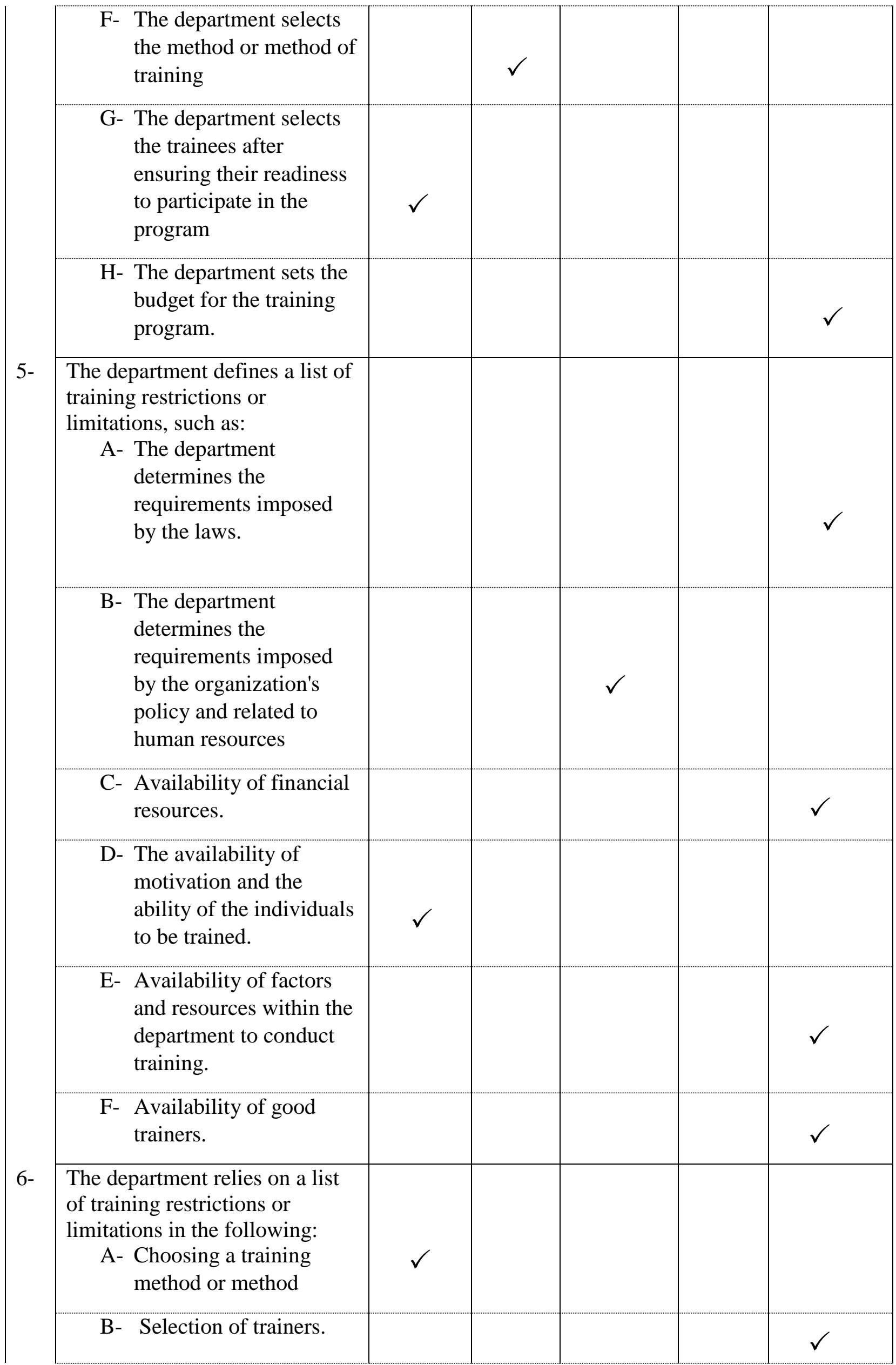




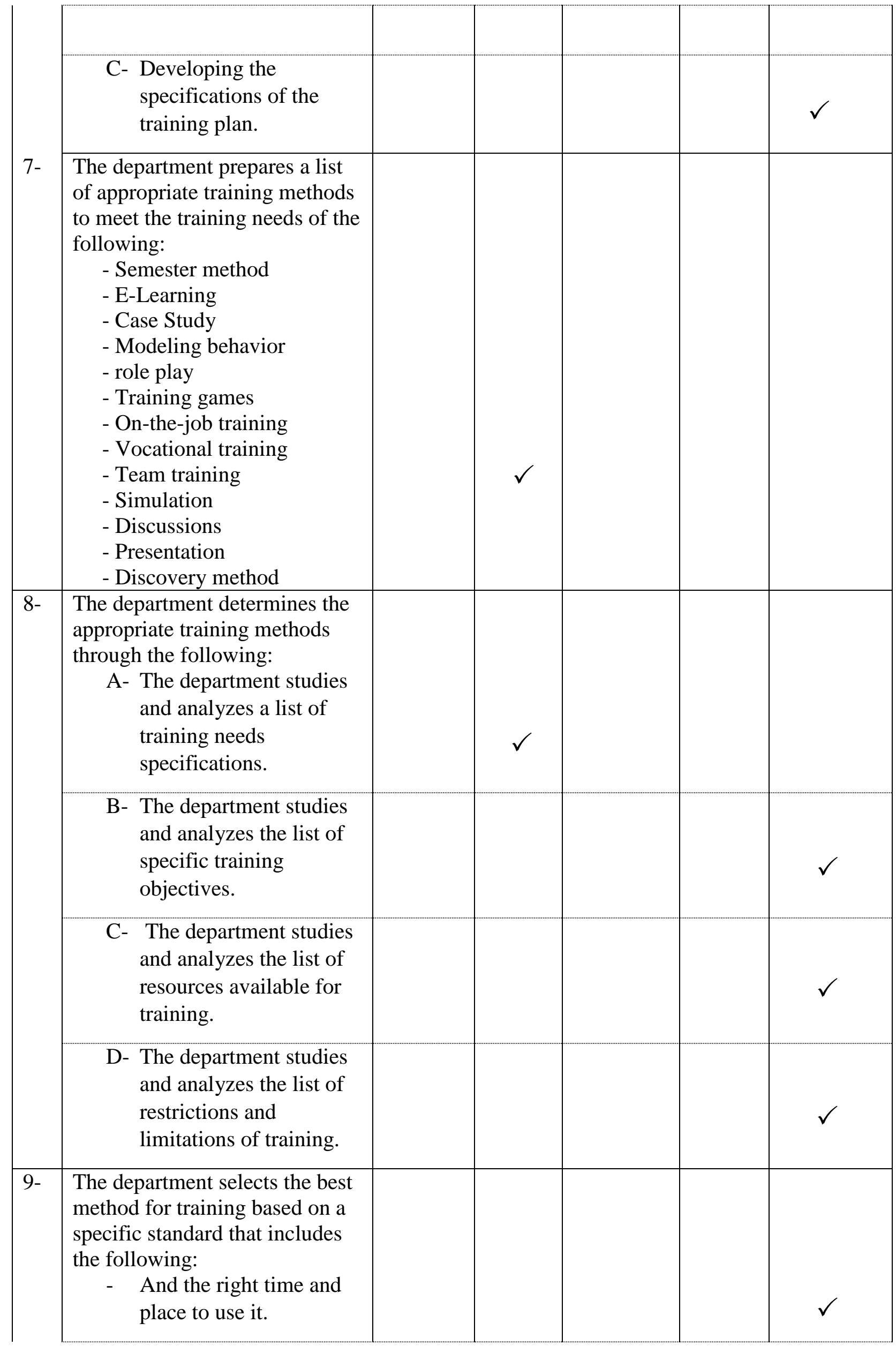




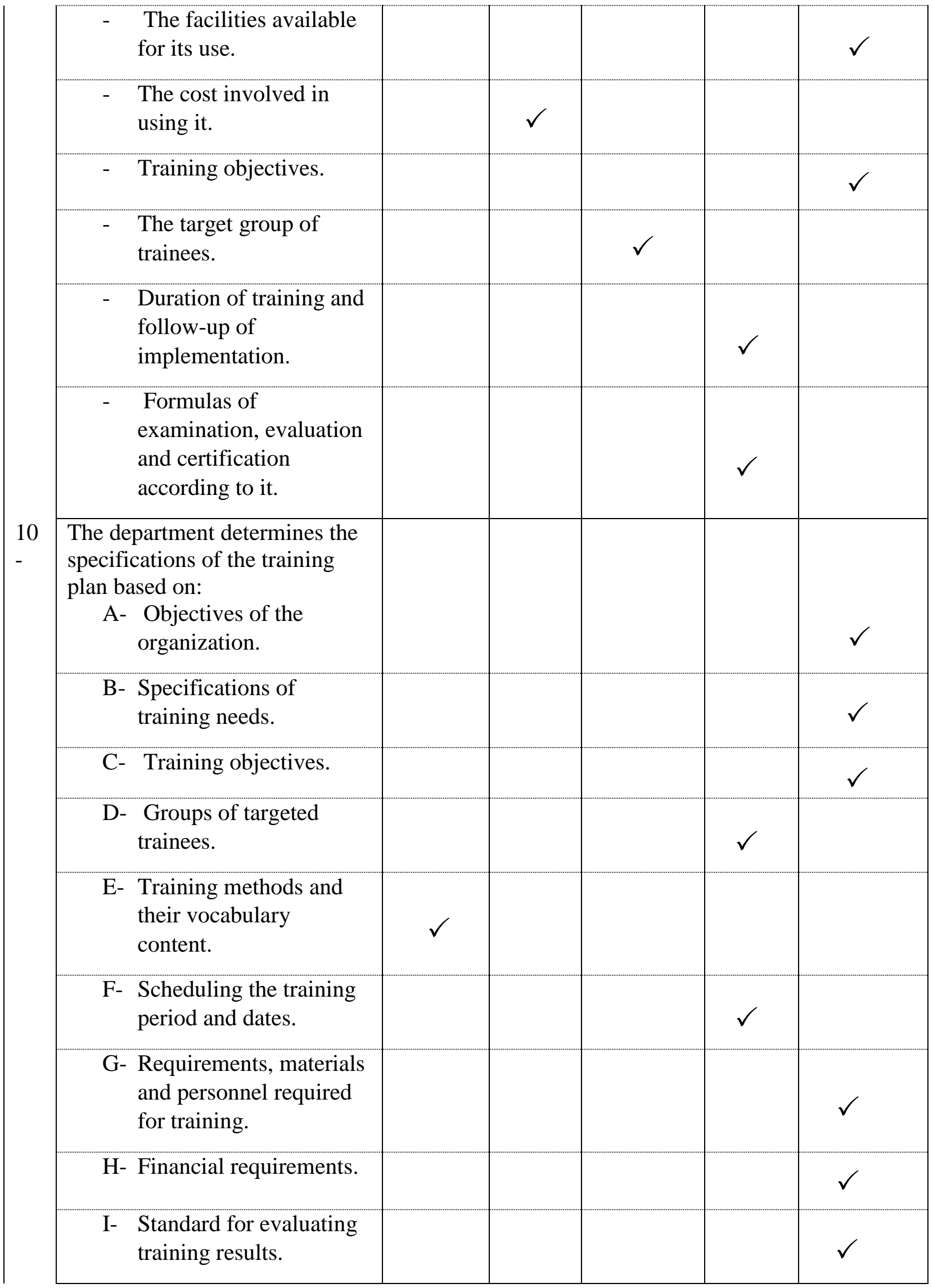




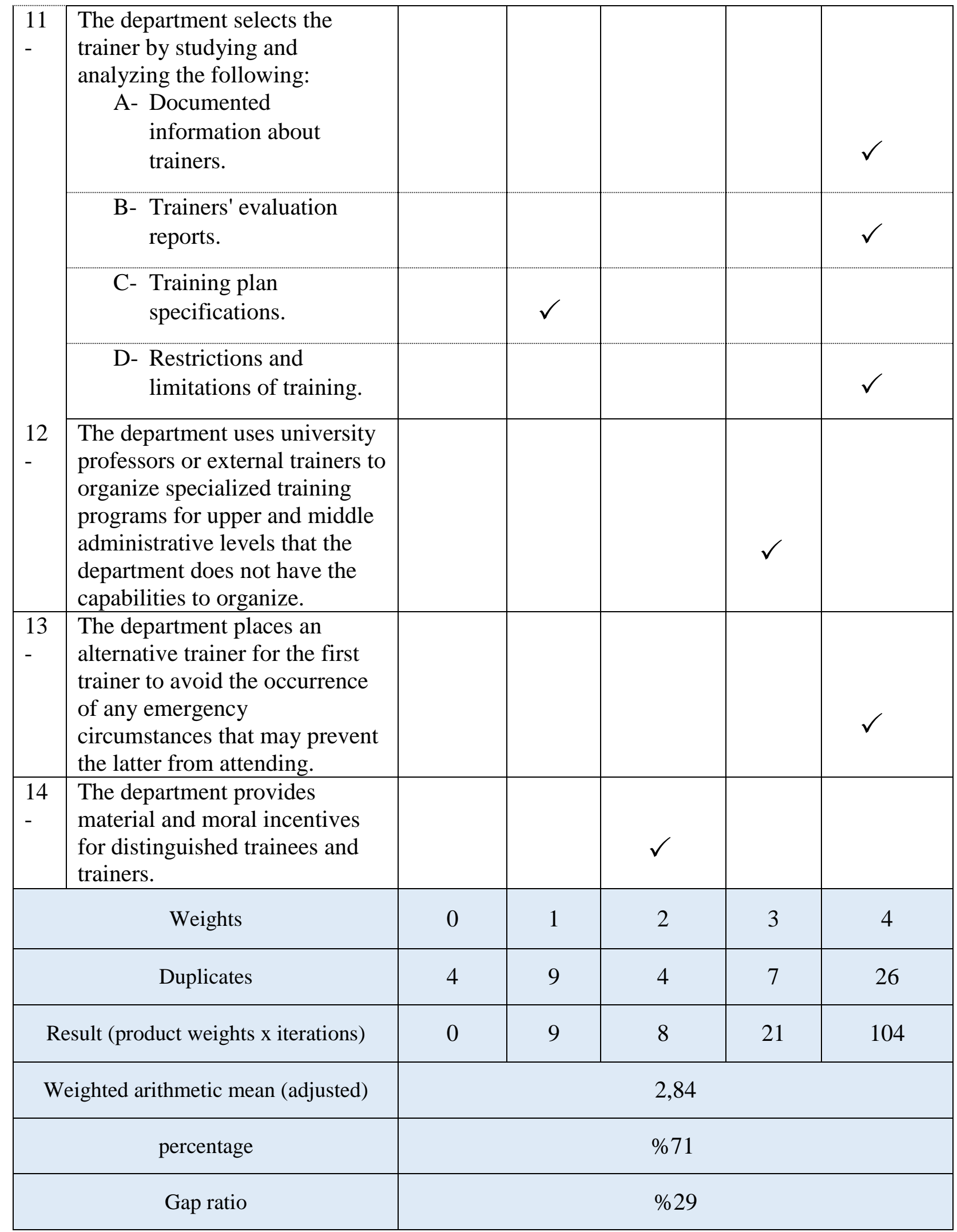

\section{Analysis:}

Based on the checklist for (designing training programs) shown in Table (1) that the actual application of this paragraph in the researched organization according to the weighted arithmetic mean value is (2.84) out of (4), and this indicates a partial implementation of the requirements of this paragraph And with a percentage reaching (71\%), which led to a gap, and at a percentage $(29 \%)$, this can be traced back to 
the strengths and weaknesses shown as follows:

\section{strength points :}

1- The training department shall work on identifying and meeting the official requirements imposed by the applicable controls and instructions regarding the organization of training programs for employees, especially those related to the promotion and promotion of employees in various job ranks, as well as the promotion and promotion of employees to middle management positions, which require special training programs for a period of one month.

2- The training department designs the proposed training programs which are included in the (suggested courses) paragraph of the training needs selection form.

3- The training department determines the objective of the training program when circulating the training program books to the directorates in the ministry.

4- The training department adopts a set of steps in designing training programs such as (developing training content, determining the location and time of training, selecting trainers, setting the budget for the training program).

5- The training department determines a list of training restrictions and limitations, such as (determining the requirements imposed by the laws and the organization's policy and related to human resources, as well as the availability of trainers, financial resources and the necessary capabilities to carry out training).

6- Relying on the list of restrictions and limitations of the training activity in selecting the trainers and developing the specifications of the training plan.

7- The training department determines the training methods and methods by studying and analyzing the following (a list of training objectives, a list of available resources for training and a list of training restrictions and limitations).
8- Depending on the selection of the best training method on the following (the appropriate time and place, the facilities available for their use, the training objectives, the targeted trainees, the training period and follow-up implementation, test and evaluation formulas).

9- The training department determines the specifications of the training plan based on the following (the organization's goals, training objectives, training needs specifications, groups of target trainees, scheduling the training period, financial requirements, materials and staff required for training, standard for evaluating training results).

10- Reliance in selecting trainers on documented information about them, performance evaluation reports, and training restrictions and limitations.

11- Using university professors or external trainers to organize specialized training programs for the upper and middle administrative levels.

12- The training department put in place an alternative trainer for the first trainer to avoid the occurrence of any emergency situation that might prevent the latter from attending.

\section{Weaknesses points :}

1- Weakness in the methods of monitoring the implementation of the training process, because a large number of training programs are outside the training department, and therefore the results received from the training implementers are relied upon only.

2- Weakness in the work of the training department with regard to taking its role in coordination with the trainer in determining the sequence and arrangement of the topics of the training program and determining the timing of the training program as well as choosing a method or method of training, as only the trainer does this work.

3- The researcher did not notice the interest of 
the training department in the directorate regarding selecting the trainees after making sure of their readiness to learn and the extent of their motivation and ability to participate in the training programs.

4- Weakness in the work of the training department as the researcher noticed the existence of traditional and limited training methods and methods through which training needs are met.

5- Weakness in updating the documentary records pertaining to the trainers who carry out the training, which clarify their specializations and competence, and to enable the training department management to refer to it in selecting qualified trainers.

\section{2- Cause and Effect Diagram (Ishikawa Diagram)}

Cause and Effect Diagram Developed by Japanese quality expert Kaoru Ishikawa, this diagram is also called a fishbone diagram. They are powerful tools that aid quality improvement efforts to focus on finding the causes of a specific problem. The chart contains a central line, or "spine," that leads to the "effect," or problem, and a few major categories of possible causes associated with the spine. The causes of most quality problems can be grouped into general categories such as personnel, equipment, methods, materials, processes, and the environment, or the problem-specific categories can be used. Then, usually in a brainstorming session, possible subcauses, their sub-causes, etc. are identified in each category. At the end of the session, every element in the diagram is examined and removed if it is not a factor contributing to the problem. The remaining causes are closely examined, and if an association is found between them and 'impact', quality improvement efforts are directed at eliminating them (Haksever \& Render, 2013: 275-276).

Use of the cause and effect diagram (Ishikawa diagram) to analyze the gap through the idea of brainstorming in identifying the main and secondary causes of the gap by making use of information, documents, records, interviews and information recorded through visits and field experience in the place of research.

\section{- Weakness in designing training programs}

The possible reasons for the low results of this requirement compared to the checklist can be illustrated through Table (2), and the Cause and Effect diagram (Ishikawa diagram) as in Figure (6):

Table (2)

The main and potential secondary causes of the training program design implementation gap

\begin{tabular}{|c|c|c|}
\hline & Main causes & Secondary causes \\
\hline \multirow{3}{*}{1} & \multirow{3}{*}{$\begin{array}{l}\text { Weakness in implementing } \\
\text { some steps of designing } \\
\text { training programs }\end{array}$} & $\begin{array}{l}\text { Poor coordination between the training department } \\
\text { and the trainer in preparing the training content and } \\
\text { determining the sequence and arrangement of the } \\
\text { training program topics }\end{array}$ \\
\hline & & $\begin{array}{l}\text { Poor coordination between the training department } \\
\text { and the trainer in determining the timing of the training } \\
\text { program }\end{array}$ \\
\hline & & $\begin{array}{l}\text { Weak interest on the part of the training department } \\
\text { in choosing the method or style of training }\end{array}$ \\
\hline
\end{tabular}




\begin{tabular}{|c|c|c|}
\hline & & $\begin{array}{l}\text { Weakness in the diversity of activities, exercises and } \\
\text { methods used in the training programs }\end{array}$ \\
\hline & & $\begin{array}{l}\text { Weakness in motivation and financial rewards for } \\
\text { distinguished trainers and trainees }\end{array}$ \\
\hline & & $\begin{array}{l}\text { Lack of financial Customizations for designing } \\
\text { training programs }\end{array}$ \\
\hline \multirow{3}{*}{2} & \multirow{3}{*}{$\begin{array}{l}\text { Weakness in the diversity of } \\
\text { training methods }\end{array}$} & Weakness in adopting new training methods \\
\hline & & $\begin{array}{l}\text { Reliance on the style of the lectures without the } \\
\text { practical side }\end{array}$ \\
\hline & & Weak integration between theory and practice \\
\hline \multirow{3}{*}{3} & \multirow{3}{*}{$\begin{array}{l}\text { Weakness in designing } \\
\text { training content }\end{array}$} & $\begin{array}{l}\text { Weakness in contracting with training experts to } \\
\text { design programs, curricula, or training content }\end{array}$ \\
\hline & & $\begin{array}{l}\text { Weakness in the novelty of the training content and } \\
\text { the extent to which it keeps pace with the latest } \\
\text { prevailing theories and practices }\end{array}$ \\
\hline & & $\begin{array}{l}\text { Weakness in dividing the training content into } \\
\text { knowledge, skills and behaviors }\end{array}$ \\
\hline
\end{tabular}




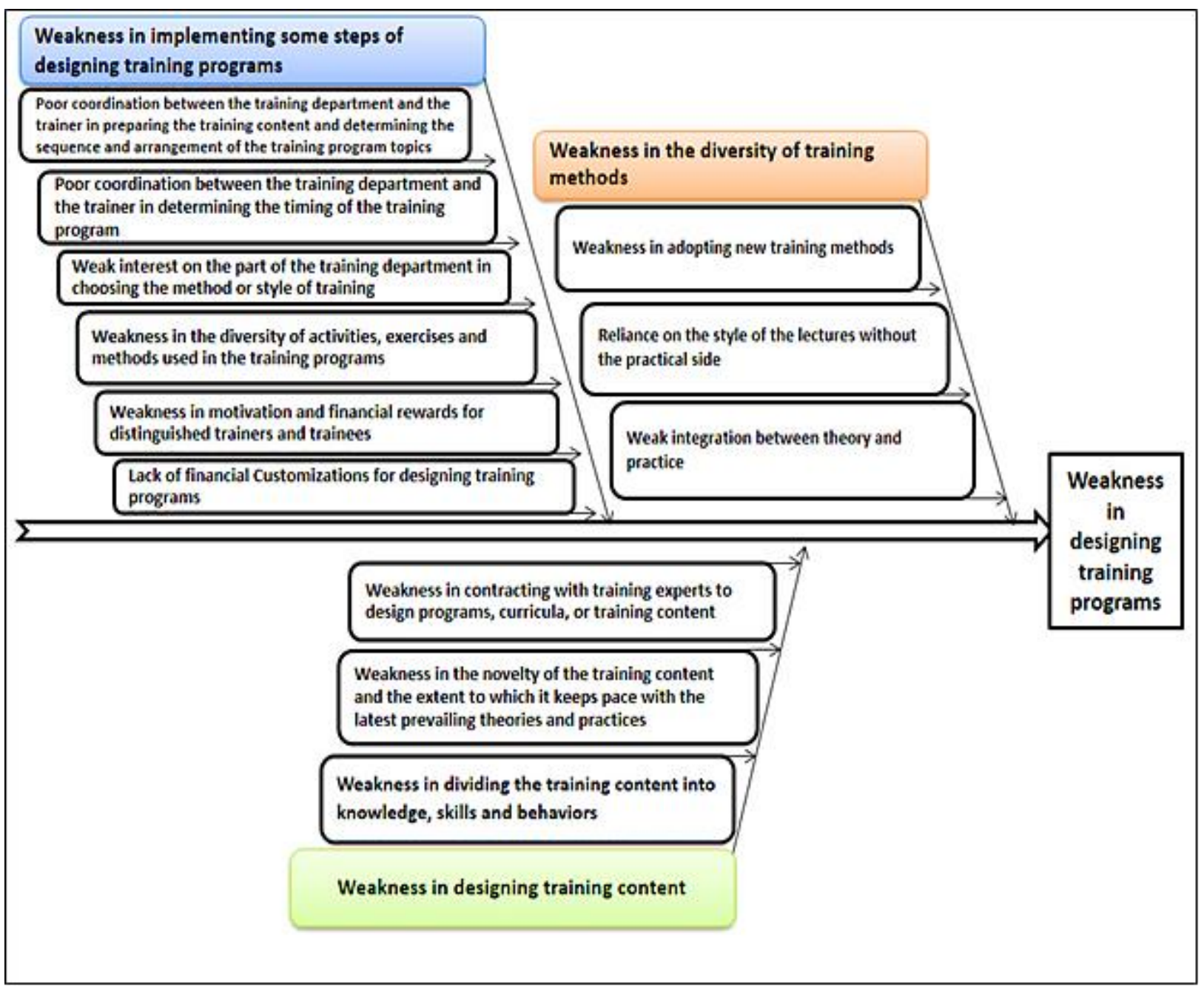

Figure (6) Cause and Effect Diagram for Designing Training Needs

Source: Prepared by the researcher

\section{The third topic}

\section{- Conclusions and recommendations:}

\section{First - Conclusions}

This topic reviews the most prominent conclusions reached by the researcher, in both the theoretical and the practical sides of the research, as follows:

1- The surveyed organization's need to review the established training activities, especially with regard to designing training programs and identifying needs. There is limited interest in the field of designing training programs and determining the actual needs of workers as well as the quality of training programs.

2- Weak interest in identifying training needs and its dimensions including (organization analysis, job analysis or tasks and individual analysis) and not giving this stage the importance that is commensurate with its large size as it represents the basis of the training process.

3- Weakness in the work of the training department in collecting detailed information about the training needs of the administrative levels (middle and lower) in the directorate, as well as the lack of a description of the level of need (lack, deficiency, sufficiency, accuracy, perfection).

4- Weakness in establishing training programs for distinguished employees and talents, as well as establishing advanced training programs that help create creativity and innovation

5- Weakness in documenting training needs in the organization and weakness in evaluating the results of previous training programs. 
6- A weak role for the training department in choosing the appropriate training method, as well as in determining the sequence, arrangement and timing of the training program terms, as well as adopting traditional and limited training methods to meet the training needs.

7- Weak interest in monitoring the implementation of training programs outside the Training Department, and reliance on the results received from the trainers.

8- Not giving importance to the issue of choosing the trainees after making sure of their readiness to learn and the availability of the desire and motivation to participate in the training programs.

9 - Weak updating of documentary records of trainers implementing training programs, which clarify their specializations and competence, in a way that helps the administration to refer to it in selecting qualified trainers.

10- Through the use of the cause and effect diagram (Ishikawa diagram), the main and secondary reasons for the gap between the actual implementation of the design of training programs in the organization and the checklist were reached, and the main reasons for this gap were (weakness in the implementation of some steps in the design of training programs and weakness in the diversity of training methods and weaknesses in the design of training materials).

\section{Second: Recommendations}

1- The necessity of adopting the scientific method in designing the training programs shown in the checklist by the Training Department in order for the training programs to succeed and thus not to waste and exhaust efforts in implementing training programs that are not feasible.

2- A computerized program is supposed to document the training activity in all its stages, especially with regard to designing training programs and updating information periodically, and this will help in the availability of a database that will facilitate the senior management to take appropriate decisions in the field of training as well as facilitate the process of preparing the annual training plan for the directorate.

3- The necessity of diversifying training methods and adopting new methods for implementing training programs, with an emphasis on the training department exercising its role in coordination with the trainer in determining the training method that is compatible with the program, as well as working to achieve integration between the theoretical and practical aspects in the training programs.

4- Working on designing and implementing training programs for distinguished employees and talents and establishing training programs that help create innovation and creativity by relying on trainers from within the directorate or contracting with specialized university professors or highly qualified external trainers.

5- The selection of trainers or training bodies (whether by internal or external training) is done accurately and based on criteria that take into account competence and sobriety.

6- The necessity for coordination in choosing the topic of the training program in cooperation and coordination between the training department or the program implementing agency and the beneficiary party, which will increase the percentage of achieving the results of the training plan.

7 - The training process must be monitored in order to identify deviations, know their causes, and address them immediately during training courses, which will help to improve the training process continuously and report on the level of benefit and the participation of workers in disseminating knowledge.

8- Subject the trainees, after the end of the training program, to observation by the supervisors, as well as asking the trainees to write a summary report on the knowledge, skills and behaviors that they have acquired through their participation in the training programs, in order to 
diagnose the extent of their benefit from the training program.

9 - Work with feedback to know the deviations of the training process in all its joints, and thus work on corrective measures and improve work procedures within each training process.

10 - The human resource management and the training department attach great importance to the training program evaluation forms, which reflect the opinions of the trainees and trainers participating in the training, and these forms will help the departments in taking appropriate decisions in light of the results and proposals that will reflect them.

11- The necessity for the Training Department and the Human Resources Department to pay attention to organizational changes within the workplace or technological changes to the external environment, in order to assess the extent of their impact on training, in order to be able to keep pace with internal and external changes and to use the latest methods in training workers.

\section{The References:}

1- Dessler. Gary, (2017)," Human Resource Management ", 6 th Edition.

2- Noe .Raymond A. , (2017)," Employee Training and Development" , 7th Edition , Published By McGraw -Hill Education, New York.

3- Noe .Raymond A., Hollenbeck .john R., Gerhart. Barry ,Wright .Patrick M.(2017),"

Human Resource Management

GAINING A COMPETITIVE

ADVANTAGE" , 10 Edition , Published by McGraw-Hill/Irwin, New York.

4- Noe .Raymond A., Hollenbeck .john R., Gerhart. Barry ,Wright .Patrick M. (2016),"

Fundamentals of Human Resource Management " , 6th Edition , Published By McGraw -Hill Education New York.

5- Haksever. Cengiz, Render.
Barry,(2013),"Service Management An Integrated Approach to Supply Chain Management and Operations", 1Edition, Published by Pearson Education, Inc.

6- Robert L. Mathis \& John H. Jackson,(2010),Human Resource Management, $13^{\text {th }}$ ed.

7- Al-Sakarneh, Bilal Khalaf, (2011) Designing Training Programs, First Edition, Dar Al-Masirah for Publishing, Distribution and Printing, Amman, Jordan. 